\title{
Téoros
}

Revue de recherche en tourisme

\section{En remontant aux sources de la toponymie...}

\section{La Commission de Toponymie du Québec}

Volume 6, numéro 2, juillet 1987

Le Saint-Laurent magnétique

URI : https://id.erudit.org/iderudit/1080499ar

DOI : https://doi.org/10.7202/1080499ar

Aller au sommaire du numéro

Éditeur(s)

Université du Québec à Montréal

ISSN

0712-8657 (imprimé)

1923-2705 (numérique)

Découvrir la revue

Citer cet article

La Commission de Toponymie du Québec (1987). En remontant aux sources de la toponymie... Téoros, 6(2), 3-3. https://doi.org/10.7202/1080499ar d'utilisation que vous pouvez consulter en ligne.

https://apropos.erudit.org/fr/usagers/politique-dutilisation/ 


\title{
En remontant aux sources de la toponymie...
}

\author{
par la Commission de Toponymie du Québec
}

Jusqu'aux dernières années du XVII'siècle, l'unique chemin qui relie Québec à Montréal, et ces villes à la campagne, reste le Saint-Laurent et ses rivières tributaires.

Canots, voiliers, barques à rames ou à voiles sillonnent cette route naturelle et portent d'une ville à l'autre nouvelles et marchandises, parfois avec un retard qui peut atteindre trois semaines quand les elements ne sont pas favorables.

Le spécifique Saint-Laurent apparaît comme toponyme dans des traductions de la narration de Jacques Cartier concernant son voyage de 1535-1536: d'abord dans une traduction en espagnol en 1552 et une autre en italien en 1556. Dans ces traductions, l'appellation baye sainct Laurens, attribuée par Cartier en 1535 à un rentrant de la Côte-Nord, est rendue principalement par grand fleuve de Saint-Laurent. Par la suite, le spécifique Saint-Laurent s"est aussi appliqué au golfe puis au cours d'eau. L'appellation la plus ancienne à avoir été consignée pour caractériser cette entité hydrographique demeure celle mentionnée par Jacques Cartier en 1535, qui est celle de grand fleuve de Hochelaga.

Cependant, ainsi qu'en témoignent certains documents, le nom peut-être le plus connu du fleuve au XVI $\mathrm{I}^{\mathrm{e}}$ siècle fut rivière $d u$ Canada. Par exemple, dans une lettre datée de 1587, Jacques Noël, petit-neveu de Cartier qui lui aussi avait remonté ce cours d'eau au moins jusqu*à la hauteur de Montréal, écrit également rivière de Canada. En 1603, Samuel de Champlain l'a aussi désigné sous ce nom. Il opta par la suite pour grande rivière de sainct Laurens et fleuve sainct Laurens. C'est donc au XVI' ${ }^{e}$ siecle que $I^{\dagger}$ appellation fleuve SaintLaurent a fini par supplanter ses concurrents.

Depuis le $X V T^{*}$ siecle, des segments de cette voie d'eau ont parfois pris des appellations spécifiques. Par exemple, lors de son expédition de 1542-1543, l'explorateur français Jean-François de La Roque de Roberval nomma France Prime la section comprise entre l'ile d'Orléans et la localité de Cap-Rouge. Selon le géographe anglais

"Organiame gouvernemental.
Richard Hakluyt, ce nom de France Prime a été attribué par Roberval en hommage à François Premier, roi de France. Aux $\mathrm{XVII}^{e}$ et XVIII ${ }^{e}$ siècles, le Saint-Laurent, entre les lacs Saint-François et Ontario, a parfois été indiqué sur les cartes sous les noms de rivière des Iroquois et de rivière de Cataracoui. Cette dernière appellation venait du nom amérindien du fort Frontenac, aujourd'hui Kingston en Ontario. Ces

deux toponymes devaient disparaitre et être remplacés par fleuve Saint-Laurent

Rappelons enfin que les nations amérin. diennes ont chacune leurs appellations pour identifier le fleuve. En montagnais, le Saint-Laurent se dit Wepistukujaw Sipo ("rétrécissement"'), en abénaquis Moliantegok ("à la rivière Montréal"), en mohawk Raiatatokenti et Raoteniateara (aucune traduction connue). $f$

\section{Le Saint-Laurent, mémoire du pays}

\section{par Normand Cazelais*}

Le Saint-Laurent est fils de la mer de Champlain et dauphin du golfe de Laflamme; il est héritier du Grand Glacier qui a varlopé en temps d'inhumaine mémoire la table bosselée du Bouclier et laissé, à son retrait, terrasses dans la plaine et plages sur les hauts versants des montérégiennes. Mais pourquoi, oui pourquoi, une légende ne nous ranconte-elle pas que le Saint-Laurent est né d'un déchirement d'amour ou d'un long hozanna?

Ohé, là-bas! m'entendez-vous? L'eau porte-elle ma voix jusqu'à vous? N'étiezvous pas marin sur ce navire, l'Emérillon? Que vous a confie ce fleuve, cette rivière de rivières? Vous qu'il a, les premiers, accueillis à sa cour, en ses vastes eaux, avez-vous pu parcourir son domaine avec lui? L'avez-vous vu, dites-moi, recevoir la Romaine, l'Aguanus, le Richelieu, I'Outaouais, tous ses émissaires, ses vassaux, grands et petits, venus lui rendre compte de ses terres hautes et vierges possessions, venus lui raconter le Midi comme le Septentrion? A-t-ill, dites-moi, calmé les plus nerveux, dompté les rapides et bouillonné a la rencontre du Saguenay, fjord qu'on m'assure être son grand ami? Vous a-t-il permis d'ecouter avec lui bruisser dans le soir la forêt de ses chênes, de ses

*Normand Cazelais, góographe, chroniqueur de tourisme, est membre du comite de rédaction de Téoros et coordonnataur du present numéro. hêtres et érables, de ses ormes, de ses frênes et bouleaux, de toute sa forêt qui se découvre chaque année devant sa douleur automnale?

$D^{*}$ Anticosti à la plaine, le Saint-Laurent est golfe, estuaire et fleuve. Il est l'un, l'autre et les trois. Et bras de mer et sang de la terre. Il est veine battante aux caresses de juillet, il est strate et métal dérobés par le gel, il est nerf tendu entre l'Ancien et le Nouveau Monde. J'y colle l'oreille et entends le cri de l'outarde, l'écho des bris de glace et du grand craquement des ponts effondrés; je retiens mon souffle, je n'entends plus le foc claquer mais seulement gronder les moteurs et mugir les sirènes. Le Saint-Laurent n'a pas tout oublié. D'ailleurs, il n'a rien oubliê, il préfere parfois ne pas se rappeler.

Oui, le Saint-Laurent est mémoire du Québec: il a mémoire de ces rangs développés, perpendiculaires à ses eaux, en longues lanières parallèles; il a mémoire du fronteau, du premier voisin et du trécarré, des seigneuries et de leurs moulins où les barques y menaient le grain, de Sainte-Lucesur-mer, de Métis-Beach et des premières stations balnéaires recherchées des Américains. Il porte encore l'entaille des pre-

(suite a la page 32 ) 